\title{
The complexity of children's involvement in school bullying
}

A version of this article is published in Journal of Children's Services, Accepted

12 Ocober 2017 and published December 2017.

\author{
Abstract \\ Purpose - The complexity of children's involvement in school bullying from the \\ child's perspective is examined.
}

Design/methodology/approach - A Foucauldian perspective provides a more nuanced approach than traditional understandings to examine the fluidity of power which involves 'grey' areas; struggles between pupils, and pupils and teachers; and takes into account systemic factors. Data is drawn from observations, focus groups and individual interviews with children aged $10-16$. Findings - Children explained how pupils, teachers and inequalities inherent in school contributed to their involvement. Children felt coerced into reinforcing societal inequalities whereby the 'vulnerable' were susceptible to victimisation and pupils can achieve status through bullying. Several working-class males who had learning difficulties felt 'picked on' by their peers and teachers, and subsequently retaliated aggressively.

Research limitations/implications - Findings from this relatively small sample provide insight into children's unique experiences and how they are produced within wider systems of knowledge which differ from traditionally accepted discourses.

Practical implications - Drawing upon the voice of pupils who contribute to developing school strategies to overcome bullying is recommended. 
Social implications - Traditional ways of identifying 'bullies' can be used to target those already marginalised whilst more sophisticated bullying is usually accepted and approved.

Originality/value - The complexity, fluidity and multi-faceted nature of children's involvement is highlighted. Children discussed the maltreatment they experienced from pupils and teachers but did not realise how they may have subjected them to bullying.

Keywords Bullying, school, children, power, teachers, child's voice Paper type: Research paper

\section{Introduction}

Traditional and new approaches

Whilst much has been written about the psychological problems associated with pupils who engage in bullying, relatively little attention has been paid to pupils' perceptions of their involvement and underlying issues behind this behaviour. Children who engage in bullying have been described as a minority who lack empathy and are more likely to be involved in crime and be excluded from school (Ofsted, 2003; Monks et al. 2009). Aggression becomes bullying when it is repeated, intentional and involves a clear imbalance of power. This definition was developed by Olweus (1993) but most researchers identify bullying in similar ways (Terasahjo and Salmivalli, 2003; Rowe et al., 2008; Gumpel et al., 2014). Some fluidity is incorporated as it is recognised there are 'bully/victims'. 
Social psychology considers how bullying is influenced by individual traits and social interactions (Sondergaard, 2012). The social-ecological model provides a dynamic approach at multiple levels: individual, peers, school and communities (Swearer and Hymel, 2015). The social psychological approach, and in particular the social-ecological model, provide a more contextualised understanding. All approaches acknowledge power imbalance and have enhanced understanding and led to preventative methods. Along with the traditional approach, social psychology and social-ecology rarely provide a nuanced approach to power which examines the complex ways in which power operates (and can be abused) through institutional structures and social inequalities (systemic) from the child's subjective perspective, taking ambiguities into consideration. Traditional definitions are usually adult-centred, which can omit children's knowledge and decontextualise bullying. However, Morita (1996) provides a nuanced approach which this study pursues. He argues that bullying involves a spectrum of negative behaviours that are 'grey' and range from mild teasing ('light grey') to criminal damage ('dark grey'). Teasing can be amusing but it has also been associated with suicide. It is considered a 'grey' area ranging from 'light' to 'dark' grey. Teasing which causes distress is considered as bullying but teasing which appears playful could still be bullying.

Through examining children's perceptions, bullying is investigated within the context it occurs, which enhances understanding of their experiences (Ryan and Morgan, 2011, Warner and Little, 2015, Canty et al., 2016). Green (2001) asserts that an individualistic approach underestimates the prevalence of bullying and misunderstands its nature. All pupils are affected by a climate where bullying 
exists - for example, if they are frightened of being humiliated for answering a question wrong which highlights fluidity of involvement. Bansel et al. (2009) argue that bullying is an unacceptable but intelligible extreme of regular networks, practices and relations of power. Bullying achieves leadership and control through the normative regulation of individuals which can position certain individuals as powerful. However, positions can change as individuals can influence their ordering of relational practices and norms. Bansel et al (2009) is expanded on in this article by investigating interactions between pupils and teachers, and how pupils attribute responsibility for their bullying.

\section{A Foucauldian lens to reframe bullying}

Recently, there has been a shift towards using Foucault's work to expand understanding (Jacobson 2007, 2010; Bansel et al., 2009; Walton, 2010; Horton, 2011; Schott and Sondergaard, 2014; Kousholt and Fisker, 2015). Foucault emphasises the role of institutional and societal factors in school, since this is the place where bullying occurs (Horton, 2011). How power operates through normalisation and surveillance is examined. According to Foucault (1979), normalisation and surveillance are significant forms of disciplinary power which have replaced sovereign power. Sovereign power refers to the monarchical central power of the King, whereas disciplinary power operates through social control by rules, procedures and regulation. It creates meaning and influences thoughts, behaviour and perceptions. Disciplinary power is institutionalised through coercion and acceptance. In school, individuals become the object of manipulation and conditioning, with institutionally structured days and little control (Foucault, 1979). 
Normalisation creates hierarchies and divisions between normality and difference through ranks and measures, for example, through assessment results which measure the value of individuals. Normalisation instils homogeneity by defining standards whereby those identified as 'different' are construed as aberrant as pupils develop awareness of what standards are expected. Individuals become trained to impose self-discipline to conform to organisations which control them and achieve success, such as through successful examination results (Danaher et al., 2000).

Foucault (1979) uses panopticism to explain how disciplinary power makes individuals visible through surveillance. Panopticism refers to the panopticon which was a tower placed in the centre of prison where cells encircle a central observation point; everyone is watched. Those who do not conform to norms experience surveillance which 'increases the visibility of individuals through which one differentiates and judges' (p. 184). Surveillance can provide prisons with offenders, which the prison transforms into delinquents who are targeted by police supervision, which sends many back to prison. Through surveillance and normalisation individuals become targeted, marginalised and subject to increasing punishment and bullying when their behaviour does not conform to expected social and/or educational norms. Power operates subtly, for example through fear rather than overt physical punishment. The ability to exercise, and resist, power is dependent upon how individuals are positioned and position themselves in relation to systemic power imbalances such as gender and whether they are pupils or teachers (Horton, 2011; Kousholt and Fisker, 2015). 


\section{Normalised bullying}

Although it has been suggested that most children are bystanders who dehumanise those victimised and ignore their feelings (Sullivan et al., 2004), Gumpel et al., (2014) found that all participants reinforced bullying (a minority defended victims). Bullying may be so prevalent that it is accepted as a normative, albeit negative, aspect of school (Rowe et al., 2008). Foucault's work can connect bullying with societal understandings of normality and abnormality by examining the bullying of 'ordinary children' (Horton, 2011). Bullying has been justified whereby victimised children were perceived as negatively deviant and deserving of hostility (Terasahjo and Salmivalli, 2003; Thornberg, 2015). Moral disengagement is associated with bullying and can involve blaming the victim, seeing the victim as deserving, minimising one's agentive role ('I didn't start it') or distorting the consequences ('it was for fun') (Hymel et al., 2010). To add complexity, children's perspectives of what contributes to their involvement and perspectives of children not typically considered as 'bullies' are investigated in this study.

Sondergaard (2012) argues that bullying is a reaction to children's expectations of becoming group members and their fears of being isolated. 'Correct' behaviours are established through boundaries between group members and the 'Other' as empathy diminishes because children do not realise how they can include isolated peers. She found that if a victimised child 'hits back' they are not perceived as being bullied by adults. Instead they are recognised as the problem whose behaviour needs regulating. Children who retaliate can be excluded from the group and targeted by teachers but the child who intensifies attacks may not 
be punished. Sondergaard (2012) focuses primarily on peer relations rather than systemic factors which the study reported in this article addresses. Her study raises questions such as to what extent children reinforce norms instilled by teachers and how might pupils marginalise teachers?

Systemic bullying comprises institutional and societal inequalities which target and marginalise certain groups and individuals and cause distress, for example, when children in the lowest class are upset because they feel 'thick'. Lynch and Lodge (2002) found that children felt stigmatised because they were in the lowest set. Assessments polarised groups, causing hostility - especially towards the cleverest pupils. Systemic bullying is entangled within bullying between pupils, and pupils and teachers.

Bullying could be a motivation to navigate power relations and achieve status; bullying may be admired rather than pathologised (Jacobson, 2010; Horton, 2011, Horton et al., 2015). Children who engage in bullying are not necessarily well liked but they can have high status with peers (Caravita et al., 2009). Gumpel et al., (2004) found that children who persistently engaged in bullying made decisions on who was included in social activities and were on good terms with teachers. Occasionally children reinforced their teachers' authority through bullying. They argue that one teacher formed an 'alliance' with a child who frequently bullied children because she was too weak to control the class. 


\section{Bullying and the school system}

Hepburn (1997) contends that traditional approaches situate bullying within fixed personality traits. However, teachers are under surveillance to place children under observation. Children who do not perform to standards expected experience surveillance. She found that teacher-pupil relationships revolved around bullying. Pupils who were identified as misbehaving were given daysheet forms where their 'bad behaviour' was reported, whilst the misbehaviour of others was not. Children who are frequently punished can become angry and disengaged (Foucault, 1979), and they may retaliate and engage in bullying.

Walton (2005) argues that the individualistic approach has placed responsibility for bullying on a pathologised minority who are identified as 'bullies' rather than focusing on the maltreatment 'ordinary' pupils may engage in. Interestingly, victimisation of lesbian, gay and bisexual individuals has been perpetrated more by groups than by individuals (Rivers and Cowie, 2006). Ryan and Morgan (2011) assert that bullying is a manifestation of institutional operations of power which are hierarchical, differentiated and shifting. How children can feel victimised by their teachers is examined in this paper. Teachers are more aware of bullying by children who are frequently in trouble and victimised by pupils, whilst bullying which involves 'obedient' pupils is often undetected (Frey, 2005).

Walton (2005) asserts that research has yet to fully address how bullying is characterised by negative associations with difference, such as social class which this study investigates. Working-class males are often pressured and rewarded by their peers for behaving more overtly aggressively (Willis, 1977, Mac an Ghaill, 
1994). Consequently, they are punished and placed under the attention of professionals, thereby creating an environment of tensions and conflict from which bullying derives (Walton, 2010). Compliance approved of by peers in middle-class females is valued in school (Reay, 2001). Children perceived as obedient may engage in bullying through reinforcing educational norms tolerated by teachers.

Although teachers exert power over pupils, pupils can wrestle power from teachers who are positioned as 'weak'. Bullying may support standard practices by supervising and pressuring teachers who don't conform to change their behaviour (Ryan and Morgan, 2011). Pupils' perceptions of how they can bully teachers are examined.

\section{A multi-faceted examination of bullying}

Researchers who have adopted Foucault's work tend to adopt a theoretical rather than an empirical approach which focuses on children's perspectives. An exception is Horton's (2011) thesis, which used Foucault to frame his ethnographic study in Vietnam. Although Bansel et al. (2009) examine children's views, it is through the retrospective experience of researchers rather than on the child's perspective. How children are active agents who influence and are influenced by their environment and interactions is considered in this article (Christensen and James, 2000; Corsaro, 2005; James, Jenks and Prout, 2005). Children's perspectives are drawn upon in this study because their interpretations are central to understanding their responses (Prout, 2000). 
Bullying between pupils, and between pupils and teachers, is examined in this article using a Foucauldian lens. Bullying is slippery and nuanced; involves 'grey' areas and power struggles; is multi-layered and interpreted differently to specific aggression as identified by the individual approach. The study objectives are to analyse what factors children feel contribute to the maltreatment they engage in (overtly or covertly) and where they attribute responsibility for their behaviour (themselves, their peers, teachers, and/or school).

\section{Methodology}

Methods and participants

Children were drawn from four state secondary schools (Woodlands, Northfield, Parklane and Townville), a Private Secondary School and a Pupil Referral Unit (PRU). One child in the overall sample was at a Primary School (year six). Schools were from the district of a medium-sized city in the north of England which was predominantly white working-class. The GCSE pass rate in the state secondary schools was below national average. The Private School had a good reputation locally. Children in the state schools lived within a three-mile radius of their respective school. Woodlands was in a deprived location selected to examine issues with social class which had arisen in the Private School. In the PRU and Private School most children travelled between zero and nine miles.

Qualitative approaches were used: observations, focus groups and individual interviews. Observational data was generated through field notes taken in the classroom, playground and as children moved between lessons. Four days of 
observations were made at each of the following schools: Woodlands; Northfield; Private School; and PRU.

Table 1 demonstrates the number of focus groups and details of participants and their gender.

Table 1: Focus groups, and number of participants (males, females)

\begin{tabular}{lcccc}
\hline \multicolumn{4}{c}{ Education Establishment } \\
\hline & $\begin{array}{c}\text { Woodlands } \\
\text { School }\end{array}$ & $\begin{array}{c}\text { Northfield } \\
\text { School }\end{array}$ & Private School & Total \\
\hline Focus groups & 4 & 2 & 4 & 10 \\
Participants & $21(11,10)$ & $12(3,9)$ & $24(12,12)$ & $57(26,31)$ \\
\hline
\end{tabular}

All participants observed were from Year 7 (11-12 years). Groups of children from all four classes in Year 7 participated in Woodlands and the Private School. In Northfield, pupils from two classes participated. Table 2 shows the number and profile (age, gender) of participants in the focus groups and individual interviews.

Table 2: Number of participants (males, females) and age range in individual interviews

\begin{tabular}{|c|c|c|c|c|}
\hline & $\begin{array}{l}\text { Forms of } \\
\text { Interviews }\end{array}$ & & & \\
\hline & $\begin{array}{l}\text { Private } \\
\text { School }\end{array}$ & PRU & $\begin{array}{l}\text { Snowball } \\
\text { Sample }\end{array}$ & Total \\
\hline Participants & $11(5,6)$ & $11(8,3)$ & $10(5,5)$ & $32(18,14)$ \\
\hline $\begin{array}{l}\text { Age Range } \\
\text { (years) }\end{array}$ & $11-12$ & $14-16$ & $10-15$ & $10-16$ \\
\hline
\end{tabular}

Note. Nine children were interviewed twice ( 7 males and 2 females).

I had previously worked as a supply teacher in Northfield and the Private School, and as a teaching assistant in the PRU where teachers in these schools approached 
me to conduct research. Focus groups and individual interviews consisted of volunteers. The snowball sample was used because it became difficult to regain access as schools were frequently busy. It comprised individual interviews from three schools (Primary, Parklane and Townville) with children I knew who lived locally and who knew other pupils. Children's experiences were focused on rather than their age as a signifying factor.

\section{Roles of Researcher}

Data collected in Northfield and the Private School were on pupils who attended when I had finished teaching. I did not work in the schools whilst I was collecting data. Knowing certain children in the snowball sample (for example, Jack and Nicole) before data collection increased my awareness of the issues discussed, and we had formed a trusting relationship. I explained how interviews were different to our usual conversations which helped them understand how it was different to our usual interactions and avoided exploiting relationships. In the PRU, children may have perceived me as being in a position of authority (although I was a teaching assistant there rather than a teacher). I interacted with children at break-time and between lessons, and did not give orders as I would have done as a teaching assistant/teacher. Children were reassured of their confidentiality when a minority in the PRU asked if I would 'tell a teacher'. From having worked previously in Northfield, the private school and the PRU I became more aware of the schools' social and cultural contexts, and learnt more about interactions with pupils and teachers to develop relevant areas to investigate. The analysis focused on data formally collected rather than on prior information in 
order to avoid initial judgments impacting on analysis and to ensure that consent had been obtained officially.

\section{Ethics}

Participants were informed that their data would be treated confidentially and of their requirement to maintain confidentiality in focus groups. Consent was voluntary and obtained from participants and parents, or head-teachers in loco parentis. Participants were debriefed and informed of their right to withdraw. Pseudonyms are used here for participants and schools. The risk of potential harm was monitored and reflexively assessed prior to, during and after interviews. In focus groups where children teased and may have upset others I provided a supervised environment where I intervened by discussing how distressing bullying can be. At the end of interviews, I asked participants how they felt and if they were distressed. I ended one focus group early because one child, Rachel (Woodlands), was upset. I listened to Rachel express her feelings privately. Rachel gave me permission to speak with the participants about the impact of their behaviour and those who uspet her subsequently apologised to her. After interviews I provided advice on how children could access support if they felt upset and contacted deputy heads to ask if participants were distressed who informed me that they weren't. Formal ethical approval was received from University of Huddersfield.

\section{Data analysis}

Individual cases were examined with their ambiguities and complexities. A list of characteristics associated with bullying was derived from reviewing the academic 
literature and speaking to children about what they considered as bullying, for example, calling others hurtful names and physically violent interactions. These behaviours were considered on a spectrum of bullying which included 'grey' areas that varied in severity. Covert (for example, subtly participating in ostracism) and overt bullying (for example, physical violence which clearly caused distress to others) was investigated. Aggression which is repeated, intentional and involves a clear imbalance in power is considered as clearly bullying.

Observations were used to become familiar with children, their environment and interactions, and to develop a thematic framework on which to base interview questions. They were not included more systematically in the analysis because interviews enabled in-depth attention to the child's voice in a more confidential environment than the classroom/playground. Focus groups were used to develop interview questions and examine children's interactions. The thematic framework contained questions linked to sub-headings of emerging 'themes'. In observations the thematic framework involved: 'general thoughts of school', 'grading/setting', 'discipline/control' and 'bullying'.

Individual interviews investigated perspectives in depth and open questions avoided restricting responses. Semi-structured interviews provided consistency in areas covered and freedom in attention to topics (O'Kane, 2000). Open-ended questions encouraged children to share their views and experiences. Follow-up questions emerged in response to issues raised. When a participant told me that he had been beaten up, I asked him what happened rather than sticking rigidly to the 
interview schedule. An emphasis on individual perspectives and complexity provides richer data than multiple choice questions which are usually used in studies of bullying. Although the child's voice has been interpreted, various perspectives were examined so that the focus is not on one voice.

The starting point for analysing data using Foucault's $(1979,1980)$ work focused on how power operates through normalisation and surveillance (between pupils, and pupils and teachers) and how systemic factors interweave. Children's perceptions are constructed as being entrenched in power relations, and are about what can be said and with what authority. Insights into which discourses are accepted and resisted illuminate the dynamics of knowledge production (Jacobson, 2010). Normalisation and surveillance position individuals and influence involvement. Although all individuals are observed, individuals who do not conform to social and educational standards can experience surveillance and become targeted by pupils and teachers. Resistance is imbued within power and is influenced by normalisation and surveillance.

Interview transcripts were analysed line-by-line where words on each line were annotated and commented on. A framework analysis was implemented through firstly identifying sub-themes, then broader themes and finally thematic headings. Themes provided a guide before data were analysed and were not exhaustive. A rigid and rigorous coding criterion is inconsistent with a Foucauldian approach. As data analysis progressed, I explored how themes interweaved. 
Three thematic headings emerged which were 'pupil-pupil bullying', 'daily experiences in school' and 'restricted responsibility'. See Table 3.

Table 3: Themes of research findings

\begin{tabular}{llll}
\hline $\begin{array}{l}\text { Thematic } \\
\text { Heading }\end{array}$ & $\begin{array}{l}\text { Broad Themes and } \\
\text { Sub-themes }\end{array}$ & & \\
\cline { 2 - 4 } $\begin{array}{l}\text { Bullying } \\
\text { between } \\
\text { pupils }\end{array}$ & $\begin{array}{l}\text { Forms and effects } \\
\text { (e.g. teasing). }\end{array}$ & $\begin{array}{l}\text { Bullying achieves } \\
\text { power over others } \\
\text { (e.g. popularity). }\end{array}$ & $\begin{array}{l}\text { Persistence } \\
\text { (e.g. 'bullying } \\
\text { gets worse'). }\end{array}$ \\
$\begin{array}{l}\text { Daily } \\
\text { experiences in } \\
\text { school }\end{array}$ & $\begin{array}{l}\text { Punishment and } \\
\text { effects (e.g. feeling } \\
\text { targeted). }\end{array}$ & $\begin{array}{l}\text { Intellectual ability } \\
\text { (e.g. 'not good } \\
\text { enough'). }\end{array}$ & $\begin{array}{l}\text { Teachers' role } \\
\text { (e.g. }\end{array}$ \\
$\begin{array}{l}\text { Restricted } \\
\text { Responsibility }\end{array}$ & $\begin{array}{l}\text { Agency (e.g. } \\
\text { restricted choices). }\end{array}$ & $\begin{array}{l}\text { Voice (e.g. } \\
\text { restricted voice). }\end{array}$ & \\
\hline
\end{tabular}

Note. Sub-themes are in brackets

The first of these, 'Pupil-pupil bullying', focused on bullying in its most traditional sense, for example ostracism, and analysed how pupils abused their power and had power abused over them. Several sub-themes were identified, for example, 'bullies' have lots of 'friends', whereby the strength of those who were popular was through perceived peer approval. This was placed under the theme 'bullying achieves power over others.' 'Persistence' focused on how bullying usually became more severe. 'Forms and effects' consisted of types of bullying, such as name-calling, and feelings, such as being upset.

The second thematic heading, 'Daily experiences within school', examined how power over individuals was exercised. The sub-theme 'punishment and effects' focused on how children who were punished by teachers subsequently felt and responded. 'Intellectual ability' incorporated how many children felt they were not achieving the academic standards expected and how there was hostility and 
segregation between children identified as 'swots' and children who felt they were perceived as 'thick'. The 'teachers' role' covered how teachers were positioned, such as their perceived abuse of power; this included the sub-themes of how teachers 'picked on' pupils and how 'soft' teachers were often bullied.

The third thematic heading, 'Restricted responsibility', concerned 'voice'. This was a by-product of pupils' experiences in school and examined the extent to which children felt they could express themselves freely. Children often felt there were restrictions and punishments for those who expressed to teachers their dissatisfaction with how they were treated. 'Agency' included the extent to which children exercised resistance and took into account the influence of societal (for example, social class) and psychological (for example, intellectual ability) factors; for example, several children who had learning difficulties felt 'picked on' and subsequently could not control their anger.

\section{Analysis}

\section{Bullying between pupils}

The findings demonstrate that Olweus' (1993) definition is limited in addressing children's mundane and 'grey' experiences (Morita, 1996) of bullying. In five of the six state school focus groups, 'grey' areas were evident and mainly consisted of name-calling, such as 'scrubber', and teasing, such as 'we call him Rocky 'cos he never wins' ( $5^{\text {th }}$ focus group, Northfield School).

Teasing is a characteristic of bullying which occurs on a spectrum that varies in severity. Teasing is often ambiguous and is not always clearly bullying, 
particularly when children don't appear to be upset. Teasing which upsets individuals is considered as bullying:

Interviewer: Does anyone here not call people names?

Jake: Yeah, me and Ollie

Chloe: I don't say it often; you call him (Craig) 'pees over there'

Sam: Only about four seconds ago

Interviewer: Can we imagine school without this?

Louis and Claire: No

Max: You can't imagine school like that

Sam: It'd be a lot nicer

Louis: It'd be too formal; it would have all the kids asleep

Jake: That's natural for a school, everyone does it.

(Fourth focus group, year 7, Woodlands School)

'Grey' areas prevalent in children's interactions are generally accepted (Gumpel et al., 2014). However, none of the children considered themselves as 'bullies'. The derogatory way in which Craig was referred to was persistent, involved several peers - 'everybody kept taking the mick out of me' - and 'annoyed' him. It appears to be mild bullying, making him feel slightly angry and irritated. Although most participants felt that their behaviour was normal, more serious bullying may underlie this.

There is evidence that 'ordinary' children, rather than a minority, exclude those children who are identified as 'abnormal' (Horton, 2011). Contrary to 
Sondergaard (2012), there were individual differences between children as Sam (quotation above) did not engage in or normalise the tormenting. Bullying is usually perceived as fundamental to school, which connects bullying with systemic factors. To expand previous findings (Horton, 2011; Gumpel et al. 2014), overt bullying was more apparent in state schools and lower streams (this finding is expanded on throughout this article).

Popularity was the main response to the question 'why do children bully?' 'To look better and be popular':

I don't think popular people are good, they think they're better than everybody else... and people will like them because they're bullying; they think it's good to bully people for attention... they get called 'slags' after because they're always hanging around with boys.

(Nicole, year 10, Parklane School)

Nicole demonstrates a common finding about how popularity can achieve social gains (Jacobson, 2010), such as influencing others - by 'telling you what to do' and admiration - such as 'respect' and being 'cool'. She illuminates a rare finding that enhanced visibility can subject children to bullying - for example, being called sexist names and ostracism because of the exposure and attention that popularity can provide which limits their power over peers. This expands previous research (Bansel et al., 2009; Caravita et al., 2009) by demonstrating how social power is unstable and beyond individual control. 
Children who were popular and who engaged in bullying were usually approved of by pupils and teachers:

The bullies think of ways to get to you... The person with the stick will say, 'sit in the bin or I'll put you in the bin'. They look for sticks, find the longest one they could get and start hitting each other with it. One boy might decide to pick on you and have a stick... he'd hit you, then you'd run and they'd just carry on hitting you. 'Cos they've been at school longest teachers like them, if I had the stick I'd throw it... That's where I got that bruise from, they really hurt.

(Edward, year 7, Private School)

Edward discussed how he was bullied by his friends as part of a 'game' which another pupil experienced. He demonstrates an unusual finding by highlighting how, regardless of his position, he would not engage in bullying. Although Edward appears to consent to the 'game' and his bullying is concealed. Edward shows how popular children who engage in bullying are inadvertently supported and reinforced by teachers when they bully children who 'get bullied a lot' (according to his teacher). Bullying which instils conformity to group norms (Reay, 2001) is generally accepted. These findings add depth to Frey (2005) on how obedient children's maltreatment can be undetected by teachers.

Ostracism emerged from the 'popularity' theme whereby children who were not on good terms with those who were popular were either ostracised or afraid of it. 
Being frightened of ostracism is considered to be on a continuum of bullying (Green 2001). Bullying made Peter feel ashamed, self-conscious and suicidal:

I get bullied because of my voice and my weight, [they] call me 'gay' and 'fat' ... I don't like being different to everybody. I won't walk around without a coat because I don't want everybody looking at me; I took an overdose once because it all got on top of me. (Peter, year 10, Parklane School)

Peter's profound distress regarding his experience of homophobic name-calling illuminates how it can be associated with suicide. His bullying is persistent and involves groups rather than individuals (Rivers and Cowie, 2006) although having various children watch him is an ambiguous area. Peter's experience has put his life at risk and has seeped into how he perceives himself as repulsive and unworthy.

Kimberly explains how 'geeks' are often bullied:

There's people who are weird and strange, people might call 'em 'geeks' ... they're in one group and other people are in the other group. The popular people don't mix with the other ones ... if they got something wrong they'd laugh their heads off but if someone popular got it wrong they wouldn't laugh.

(Kimberly, year 7, Private School) 
Kimberly considers herself as 'popular' and explains how she reinforces social norms rather than instigates bullying. Kimberly was favoured by her head of year who chose her to show me around for the day. I observed her actively ostracising her 'friends' by running to 'avoid them'. She blames institutional divisions and her peers for the 'harsh' way 'geeks' are treated by popular children. 'Geeks' were constructed as the 'other', which established boundaries (Sondergaard, 2012) and dehumanised them. Laughing at and ostracising 'geeks', and calling them names, indicates characteristics of bullying and humiliation concealed by group norms. Children indicate they are not intentionally bullying, rather they are aiming to achieve peer approval and status which can provide temporary protection. These findings develop Ryan and Morgan (2011) by demonstrating how children perceived bullying as being connected within peer norms and systemic inequalities, and beyond individual control. In the private school bullying through coercion to instil conformity was more pronounced than overt violence. However, 'geeks' did not experience the systemic bullying of those who were not performing well.

\section{Daily experiences in school}

Luke provides a unique perspective of how he feels inadvertently involved in ostracising children:

Before I started the football team Mr Jackson would ignore me all the time and now he's always talking to me, some people get treated better than others... Everybody treats me better... Sometimes when they're by 
themselves you feel sorry for them when you're watching them and there's no one talking to 'em.

(Luke, year 7, Woodlands School)

Luke expressed sympathy for ostracised children, which challenges Sullivan et al. (2004) by indicating that 'bystanders' may not ignore consequences. Unlike Jacobson (2010), Luke did not feel he dominated children or instigated bullying. These findings highlight the complexity of children's involvement, which expands Gumpel et al. (2014). In support of Sondergaard (2012), Luke does not consider how he contributes to bullying. However, he expressed empathy and exercised his voice about his teacher's favouritism. Luke felt coerced into ostracising certain children by teachers, peers and school norms which restricted his agency.

Hostility arose where children in the lowest streams felt marginalised, punished and targeted, which in turn perpetuated bullying. Jack was persistently in trouble for bullying. He has severe dyslexia and provides a candid account of his frustrations:

Interviewer: Why does it bother you that they ["swots"] get treated better? Jack: Because everybody's same Interviewer: What might you do to a 'swot' who annoys you?' Jack: Call 'em a 'swot', donkey-nut their tie [put their tie around a bar so they are hurt when they pull away]. (Jack, year 8, Parklane School) 
Responding aggressively to being treated unfairly was common in working-class boys: as one participant stated, '[you] can't be a swot, you might be beaten up'. Jack is physically aggressive to children who 'joke' with him. He takes out his feelings on children who torment him by 'pointing and laughing' at him, and commenting 'ah I've done mine [homework]' because he is struggling academically. He does not consider his name-calling and 'donkey nutting' as bullying because he feels provoked by their psychological bullying where he feels he is perceived as inferior. These findings expand Walton (2005) by providing evidence and a more detailed association between bullying, perceived intellectual ability and social class.

Helen demonstrates how children can lose control over their emotions when they are insulted because of their learning difficulties. A boy made her angry when he said she 'couldn't read'. She responded violently when she 'got him up to wall' (year 10, Townville School).

\section{Teachers' position}

Catherine explicitly articulated how several pupils took advantage of her teacher who couldn't manage her class, which supports the work of Ryan and Morgan (2011) about how teachers who appear to be vulnerable ('soft') can be bullied: '[I]f teacher was a push over then that was one of the best lessons, she got it for the rest of the year' (year 11, PRU). Children can take pleasure in bullying teachers when opportunities arise. However, there was more conflict between teachers and pupils in the lower sets and PRU: 
Holly and Anna: I feel thick

Danni: I'm thick; teachers are harder on us and take things out on us ...

Anna: I hate teachers

Sally: Bridgette's not nice now she shouts at teachers; she calls Mr Morris

Spit-nose

Anna: 'Cos he's gay, he shouts at you for getting you planner out

John: He gives you late marks for coming 20 seconds late

( $5^{\text {th }}$ focus group, year 7, Northfield School)

Evidence is provided of how children who felt marginalised by the education system and provoked by teachers sometimes bullied them, which develops Walton's (2010) assertion. In certain cases children bullied their teachers because they were retaliating to feeling targeted, which expands Ryan and Morgan (2011). Working-class children are often encouraged by their peers to be aggressive to teachers, which contributes to them feeling 'picked on' and not accepting responsibility. However, in the private school teachers were more respected and spoken about more favourably: 'all the teachers are great' (Steven, ninth focus group, year 7, Private School). New insight is provided in this study into the nuanced power relations between pupils and teachers and how bullying arises.

Restricted responsibility

Maria, who had just moved to a new school, felt ostracised: 
My teacher came into classroom and said, 'tell me when you stop arguing girls, cos Tanya feels piggy in middle'. [I feel] left out; cos they always sit together and when I ask them if I can sit next to them, they're like, 'I'm sitting next to Tanya'.

(Maria, year 6, Primary School)

Maria said she felt 'angry' as a consequence, which may have contributed to her not wanting to affiliate with Emily 'I don't want to sit on the same table as her'. However, Maria did not reflect on how her avoidance of Emily may have caused her distress and how Tanya felt torn. Power is fluid and dynamic as pupils exclude and upset each other. Maria's teacher considers the conflict as 'arguing' and expects the children to stop voluntarily. She does not investigate what underlying issues are contributing to the conflict or whether there is bullying. Maria feels it is impossible to resolve - 'it's never gonna be better' - and is grappling with unhealthy relationships in which she feels entrapped. Maria presents an unusual finding about how nuanced bullying can be, which adds substance to the 'grey' areas (cf. Morita, 1996).

Males from working-class backgrounds who had learning difficulties (or females who displayed these characteristics) often felt targeted by their peers, teachers and the school system. Aggressive behaviour achieves power over peers but punishment from teachers (Mac an Ghaill, 1994):

They kicked me out for fighting... I got bullied in primary school. That's why I don't let no-one bully me now. It was all way through primary school 
until year six when I turned round and hit 'em... that's what got me into fighting.

(Carl, year 11, male, PRU)

Carl, who stopped children bullying him when he retaliated, was permanently excluded from school. Permanent exclusion from school for being physical violent was quite a common experience for pupils in the PRU which Carl makes explicit. Fighting is considered a violent interaction which is a characteristic on a continuum of bullying. It involves an abuse of physical power likely to cause physical and potentially psychological harm. Aggression towards an object which does not cause distress to individuals is not considered to be bullying. The extent to which fighting is bullying depends on individual experiences and the harm imposed/experienced.

Carl does not consider his behaviour to be bullying because the psychological bullying he has endured has contributed to his aggressive response which stopped the bullying (although he lost some power when he was 'hit back'). His overt aggression towards his psychological bullying meant he was identified by teachers as the source of the problem and punished. Children who bullied Carl were not punished and he was not recognised as a victim (cf. Walton, 2005; Sondergaard, 2012). These findings enhance existing research (Frey, 2005; Jacobson, 2010; Walton, 2010) by demonstrating how being targeted by pupils and teachers can lead to increased feelings of being bullied and involvement in aggressive interactions. Since being excluded Carl felt surrounded by 'shit 
stirrers' where 'no one respects anyone', which causes him to 'lose his temper'. Carl did not appear to consider how his behaviour might be perceived as bullying.

Grant presents a general finding in children who were often in conflict with teachers:

Grant: I don't like people shouting at me. Why shout when you can talk to me?

Interview: What might you do when people shout at you?

Grant: Kick off, start swearing and chucking stuff... you can't win against a teacher. They've always got to be right. If you say something to them, if they've got something in their head, that's that, you've done it, and if you do they start going leet and then I go leet.

(Grant, year 11, PRU)

'Leet' refers to being wild and aggressive. Exercising resistance through retaliating reinforced the feeling of being 'picked on'. Grant feels his teacher abused his power over him by shouting. These data enhance current research (Hepburn, 1997; Ryan and Morgan, 2011) by considering how bullying between pupils and teachers is associated with children retaliating aggressively because they feel they cannot exercise their voice, which contributes to them not accepting responsibility. Systemic factors contribute to teachers not listening sufficiently but Grant responds aggressively to an individual by abusing his power when he behaves more verbally and physically aggressively by using offensive language, shouting and 'chucking stuff' but his teacher does not overtly 
retaliate. Grant became permanently excluded, indicating that the power imbalance was not in his favour.

\section{Conclusions and recommendations}

This study investigated the complexity of what children feel contributes to the maltreatment they engage in and where they attribute responsibility. Bullying is enmeshed within children's experiences of school and is not just caused by a minority. Children who engaged in bullying positioned in the lower streams were more frequently punished by teachers and segregated from peers. Children who felt marginalised achieved influence and esteem from peers through bullying but this enhanced conflict with teachers. Children who retaliated usually did not acknowledge how they could exercise power through transforming their circumstances. Working-class males with learning difficulties were targeted by their teachers more than others. Their aggression and exclusion led them to being further marginalised and bullied.

The traditional approach can be used to target marginalised children. Through identifying working-class males, many of whom have learning difficulties, as 'bullies', the label is used against them. However, sophisticated bullying of the 'well-behaved' is often accepted and approved of by peers and teachers. In the private school, bullying operated subtly through coercion rather than overt aggression and there were fewer tensions between teachers and pupils. Sophisticated bullying from children who were popular was usually rewarded, as it maintained systems of social inequality. Since sophisticated bullying instilled disciplinary power and was rewarded by the majority, most children did not 
reflect on the impact of their maltreatment towards others. However, the exposure of popularity can increase bullying.

Children felt coerced by peers, teachers and the school system into reinforcing bullying and it was difficult to reduce their involvement. Children focused on the maltreatment they experienced from pupils and teachers but most do not reflect on how they can respond differently to conflict or understand the perspectives of victimised children. A minority did not conform to normalised practices through bullying. Children did not accept responsibility for bullying, partly because their control, voice and agency are profoundly restricted. Empirical evidence is provided of how children feel enmeshed within abusive relationships with their peers and teachers.

It could be argued that the findings from this research cannot be generalised because they are not from a large survey. However, experiences which differ from traditionally accepted truths are presented. Unique perspectives are not necessarily typical but illuminate understanding beyond what is usually considered. Prevalent discourses can be used to target and remedy working-class males who have learning difficulties whilst sophisticated bullying is traditionally constructed as too 'grey'. The ambiguities presented here contribute to a deeper, broader and more fluid understanding of bullying than the traditional approach.

Recommendations intertwine individual and structural levels (Kousholt and Fisker, 2015). Bullying is a widespread problem partly because it is not well understood (Walton, 2010). Teachers' and pupils' knowledge of the complexity 
of children's involvement could be enhanced. Investigating children's perceptions, 'grey' areas and the role of other pupils, teachers and the school system would be worthwhile research activities. Encouraging staff and pupils to reflect on individuals' perspectives (Bansel et al., 2009), and how normalised behaviours can be perceived as bullying, could reconstruct meaning (Thornberg, 2015).

There could also be greater emphasis on the child's voice and more input into the development and implementation of strategies that resolve bullying. Including a range of individuals avoids targeting a minority. Although the individual model has been criticised for making 'individual[s] responsible' (Kousholt and Fisker, 2015: 595), findings for the study reported in this article demonstrate the importance of encouraging individuals to accept responsibility for the impact of their behaviour without pathologising them. A collective strategy could be developed from dialogue with pupils and teachers which would provide multiple agencies with enhanced knowledge of how to transform their environment. This would support individuals to resist disciplinary power by improving their social relations.

The study findings also highlight the importance of reducing systemic inequalities and understanding the complex role of teachers (Horton, 2011). Opportunities for teachers to learn how standard practices may contribute to bullying would be helpful. Professional development could be provided for teachers to show how they can be inadvertently enmeshed in conflict with marginalised pupils, such as working-class males who have learning difficulties. Teachers could be supported 
to develop alternative systems to empower pupils and encourage structural changes. Increased research about how social class is associated with bullying would be advantageous. Colleagues could share good practice of how they have overcome conflict with pupils. Further research into strategies to overcome sophisticated bullying would be beneficial. Finally, guidance and training on resolving bullying between teachers and pupils should be incorporated within anti-bullying policies.

\section{References}

Bansel, P. B., Davies, B., Laws C. and Linnell, S. (2009), "Bullies, bullying and power in the context of schooling", British Journal of Sociology of Education, Vol. 30 No. 1, pp. 59-69. doi: 0.1080/01425690802514391.

Canty, J., Stubbe, M., Steers, D. and Collings, S. (2016), “The trouble with bullying - deconstructing the conventional definition of bullying for a childcentred investigation into children's use of social media", Children \& Society, Vol. 30 No. 1, pp. 48-58. doi: 10.1111/chso.12103.

Caravita S. C. S., Di Blasio P. and Salmivalli C. (2009), "Unique and interactive effects of empathy and social status on involvement in bullying”, Social Development, Vol. 18 No. 1, pp. 140-163. doi.10.1177/0272431609342983. Christensen, P. and James, A. (2000), "Introduction: Researching children and childhood: cultures of communication”, in Christensen, P. and James A. (Eds.). Research with Children: Perspectives and Practices. Routledge, Abingdon, pp. 18.

Corsaro, W. A. (2005), The Sociology of Childhood, Pine Forge Press, London. 
Danaher, G. Schirato, T. and Webb, J. (2000) Understanding Foucault, Sage, London.

Foucault, M. (1979), Discipline and Punish: The Birth of the Prison, Penguin, London.

Foucault, M. (1980), Michel Foucault: Power/Knowledge: Selected Interviews and other Writings in Gordon C. (Ed.), Harvester, Hertfordshire.

Frey, K. S. (2005), “Gathering and communicating information about school bullying: overcoming secrets and lies”, Health Education, Vol. 105 No. 6, pp. 409-413. doi: 10.1108/09654280510630759.

Green, S. (2001), "Systemic vs individualistic approaches to bullying”, in Lurie D. J. and Zylke, J. W. (Eds.), Journal of American Medical Association, Vol. 286 No. 2, pp. 787-788. doi: 10.1001/jama.286.7.787.

Gumpel T., Zioni-Koren, V. and Bekerman, Z. (2014), “An ethnographic study of participant roles in school bullying", Aggressive Behaviour, Vol. 40 No. 3, pp. 214-228. doi: 10.1002/ab.21515.

Hepburn, A. (1997), “Teachers and secondary school bullying: A postmodern discourse analysis", Discourse and Society Vol. 9 No. 1, pp. 639-665. doi: $10.1177 / 0957926597008001003$.

Horton, P. (2011) 'School Bullying and Power Relations in Vietnam”. Doctoral thesis, Linkpoing University, Linkoping. Horton, P. (2011), "School bullying and social and moral orders", Children \& Society, Vol. 25 No. 4, pp. 268-277. doi: 10.1111/j.1099-0860.2011.00377.x. Horton, P., Lindholm, S. K. and Nguyen, T. H. (2015), "Bullying the meek: a conceptualisation of Vietnamese school bullying", Research Papers in Education, Vol. 30 No. 5, pp. 535-645. 
Hymel, S., Schonert-Reichl, K., Bonanno, R. A., Vaillancourt, T. and Henderson, N. (2010), "Bullying and morality: Understanding how good kids can behave badly", in Jimerson, S., Swearer, S. and Espelage, D. (Eds.), The Handbook of Bullying in Schools: An International Perspective Routledge, New York, pp. $101-118$.

Jacobson, R. B. (2007), "School bullying and current educational practice: reimagining theories of educational transformation", Teachers College Record Vol. 109 No. 8, pp. 1931-1956.

Jacobson, R. B. (2010), "Narrating characteristics: the making of a school bully", Interchange, Vol. 41 No.1, pp. 55-283. doi:10.1007/s10780-010-9126-z.

James, A., Jenks C. and Prout, A. (1998), Theorizing Childhood. Polity Press, Cambridge.

Kousholt, K. and Fisker, T. B. (2015), “Approaches to reduce bullying in schools - a critical analysis from the viewpoint of first- and second-order perspectives on bullying", Children \& Society, Vol. 29 No. 6, pp. 593-603. doi:

10.1111chso.12094.

Lynch, K. and Lodge, A. (2002), Equality and Power in Schools: Redistribution, Recognition and Representation. Routledge, London.

Mac an Ghaill, M. (1994), The Making of Men, Open University Press, Milton Keynes.

Monks, C. P., Smith, P. K., Naylor, P., Barter, C., Ireland, J. L. and Coyne, I. (2009), "Bullying in different contexts: commonalities, differences and the role of theory", Aggressive and Violent Behaviour, Vol. 14 No. 2, pp.146-156. doi.10.1016/j.avb.2009.01.004. 
Morita, Y. (1996), "Bullying as a contemporary behaviour problem in the context of increasing societal privatisation in Japan," Prospects, Vol. 26 No. 2, pp. 311329. doi:10.1007/BF02195508.

Ofsted (2003), Bullying: Effective action in secondary schools. HMI.465 (Ofsted Report). Stationery Office: London.

O’Kane C. (2000), “The development of participatory techniques: facilitating children's views about decisions which affect them", in Christensen P. and James A. (Eds.), Research with Children: Perspectives and Practices, Routledge, Abingdon, pp. 136-159.

Olweus D. (1993), Bullying at Schools: What We Know and What We Can Do. Blackwell, Oxford. Prout, P. (2000), “Children's participation: control and self-realisation in British late modernity", Children \& Society, Vol. 14 No. 4, pp. 304-315. doi.10.1111/j.1099-0860.2000.tb00185.x. Reay, D. (2001), “Spice girls, nice girls, girlies and tomboys: gender discourses, girls' culture and femininity in the primary classroom”, in Skelton C. and Francis, B. (Eds.) A Feminist Critique of Education, 15 years of Gender Education, Routledge, London, pp. 55-69.

Rivers, I., and Cowie, H. A. (2006), "Bullying and homophobia in UK schools: a perspective on factors affecting resiliency and recovery", Journal of Gay and Lesbian Issues in Education, Vol. 3 No. 1-2, pp. 11-43.

Rowe, W. S, Theriot, M. T, Sowers, K. M. and Dulmus, C. N. (2008), "Perceptions of bullying and non-bullying children", Journal of Evidence-Based Social Work, Vol. 1 No. 2-3, pp. 159-174. doi: 10.1300/J394v1n02_11. 
Ryan, A. and Morgan, M. (2011), "Bullying in secondary schools: through a discursive lens", New Zeeland Journal of Social Sciences Online, Vol. 6 No. 1-2, pp. 1-14. doi: 10.1080/1177083X.2011.562905.

Schott, R. M. and Sondergaard, D. M. (2014), “Introduction”, in Schott, R. M. and Sondergaard, D. M. (Eds.) School Bullying: New Theories in Context, Cambridge, New York, p. 1-19, doi:10.1017/CBO9781139226707. Sondergaard D. M. (2012), "Bullying and social exclusion anxiety in schools", British Journal of Sociology of Education Vol. 33 No. 3, pp. 355-372.

Sullivan, K. Cleary, M. and Sullivan, G. (2004), Bullying In Secondary Schools: what it Looks Like and How to Manage it. Cromwell, Trowbridge.

Swearer, S. and Hymel, S. (2015), "Understanding the psychology of bullying: moving towards a social-ecological diathesis-stress model", American Psychologist, Vol. 70 No.4, pp.344-353, doi:10.1037/a0038929.

Terasahjo, T. and Salmivalli C. (2003), "She is not actually bullied: the discourse of harassment in student groups", Aggressive Behaviour, Vol. 29 No. 2, pp. 134154. doi: 10.1002/ab.10045.

Thornberg, R. (2015), "Distressed bullies, social positioning and odd victims: young people's explanations of bullying", Children \& Society, Vol. 29 No.1, pp. 15-25, doi.10.1111/chso.12015.

Walton G. (2005) "The notion of bullying through the lens of Foucault and critical theory", The Journal of Educational Thought Vol. 39 No.1, pp.55-73. Walton, G. (2010), “The problem trap: implications of policy archaeology methodology for anti-bullying policies”, Journal of Educational Policy, Vol. 25 No. 2, pp. 135-150. 
Warner, G. and Little, M. (2016) “A place for the child's voice in children's services, Journal of Children's Services, ”Vol. 11 No. 2, doi:10.1108/JCS-042016-009, pp. 89-90, doi: 10.1108/JCS-04-2016-009.

Willis, P. (1977), Learning to Labour: How Working Class Kids get Working Class Jobs, Saxon House, Westmead. 